\title{
Het specifieke van direct marketing (1)
}

\author{
Inleiding en de omgeving
}

\section{Inleiding}

In de reeks Probleemvelden in Marketing zullen we in twee artikelen op het 'fenomeen direct marketing' ingaan. In het inleidende artikel van deze reeks (Leeflang, 1987) hebben we direct marketing (DM) gedefinieerd als een probleemveld dat zich onderscheidt van andere probleemvelden omdat men daar strategieën hanteert die gericht zijn op het tot stand brengen van structurele duurzame directe relaties tussen een aanbieder ('marketer') en zijn afnemers ('target markets'). Daarbij neemt de aanbieder traditionele activiteiten van de tussenhandel over, of hij elimineert deze activiteiten. De aanbieder die voor een direct marketingstrategie kiest zal gebruik maken van directe communicatiemiddelen zoals direct mail; directe op de respons van de klant gerichte massacommunicatie; de telefoon; een persoonlijk bezoek of interactieve apparatuur zoals interactieve kabeltelevisie. De aanbieders kunnen zich in diverse geledingen van de bedrijfskolom bevinden:

fabrikanten, grossiers en detaillisten kunnen voor een strategie van DM kiezen. Bij DM kan de transactie betrekking hebben op zowel tastbare produkten als diensten en ideeën. Verder kan voor deze strategie gekozen worden zowel in de consumentenmarketing als in de industriële marketing. Daarbij kunnen de afnemers zich zowel op binnenlandse als buitenlandse markten bevinden. In onze artikelen hebben we gekozen voor een optiek waarbij uitgegaan wordt van de aanbieders die zich richten op finale consumenten. In dit artikel zullen we eerst een omschrijving van direct marketing geven en op een aantal specifieke kenmerken ingaan. Vervolgens zullen we een beschrijving geven van de ontwikkeling van enkele omgevingsvariabelen die van invloed zijn op de ontwikkeling van direct marketing.

In een vervolgartikel zullen we ingaan op het specifieke karakter van direct marketing. Dit blijkt onder meer uit de wijze waarop markten gesegmenteerd kunnen worden wanneer men voor deze strategie kiest. Vervolgens zullen we daar beschrijven op welke wijze de produkt-, distributie-, prijs- en verkoopbevorderingsbeslissingen bij direct marketing kenmerkend zijn.

\section{Het concept 'Direct Marketing' (DM)}

Vele innovaties in marketing worden van ondernemerszijde geïnitieerd vanuit de mogelijkheden in de ontwikkelingen in de technologie. Daarbij 
spelen hoger wordende kosten, dan wel verlies aan effectiviteit van traditionele activiteiten een rol. Er wordt dan door de onderneming met de innovatie geanticipeerd op positieve afnemersreacties. Dit is echter geen doel op zichzelf. Uiteindelijk gaat het om het bereiken van een hogere produktiviteit resulterend in een hogere rentabiliteit of een hoger marktaandeel. Wanneer de afnemer op dergelijke innovaties positief reageert, wordt veelal de ontwikkeling in gang gezet tot een echte marketinginnovatie. Dit verschijnsel is op zich niet nieuw: zo werd het winkeltype 'supermarkt' destijds geïntroduceerd vanuit het streven naar vergroting van de vloerproduktiviteit van kruidenierswinkels; het produkt 'tweedrank' vanuit het streven tot overproduktiebestrijding op de vruchtensappenmarkt. De strategie van direct marketing werd geïnitieerd vanuit de ontwikkelingen in de kosten voor het distribueren van produkten en diensten, alsmede vanuit de ontwikkeling in de effectiviteit van de huiskamerbereikende communicatiemedia (de post, later de telefoon en TV) gekoppeld aan geavanceerde segmentatietechnieken.

Deze ontwikkeling in de communicatie veroorzaakte een andere (meer directe en geprivatiseerde) relatie tussen aanbieder en koper. De directheid manifesteerde zich enerzijds in het consumentengedrag: het koopgedrag van de consument versmolt als het ware met zijn communicatiegedrag. De communicatieplaats werd overwegend 'de huiskamer'. Het manifesteerde zich anderzijds ook in het profiel van de marketinginspanningen van de aanbieder: direct marketing (DM) ontwikkelde zich tot een systeem en een strategie. Opgemerkt moet worden dat we nu voornamelijk spreken over DM ten behoeve van de consumentenmarkt. Voor produkten op de consumentenmarkt was direct marktcontact van producenten met finale consumenten namelijk een relatief 'nieuw' verschijnsel. Datzelfde gold voor distributieondernemingen die traditionele activiteiten als winkelverkoop elimineerden of door direct contact met de klant lieten aanvullen. Voor produkten op 'industriële' markten was dit verschijnsel minder nieuw.

De oudste vorm van DM, postorderverkoop, ontstond in de negentiende eeuw toen leveranciers van luxe, duurzame goederen deze direct aan de consumenten aanboden en aan huis lieten afleveren. De doorbraak kwam in de Verenigde Staten. De grote warenhuizen onderkenden al vóór de Tweede Wereldoorlog de mogelijkheden die postorderverkoop bood bij geografisch geïsoleerde of te ver van het verkooppunt wonende afnemersgroepen. Per post werd de Amerikaanse welvaart in catalogusvorm geïntroduceerd bij miljoenen Amerikanen. Deze postorderverkoop sloeg sterk aan bij mensen die op het platteland woonden. Gekoppeld aan afbetalingsregelingen werd deze vorm van verkoop een groot succes. Na de Tweede Wereldoorlog kwam ook op andere doelgroepen gerichte postorderverkoop met andere produkten in zwang. Omdat de post als medium hierbij een belangrijke rol bleef spelen, luidde de verzamelnaam voor deze activiteiten 'direct mail'. Nadat ook andere communicatiemiddelen dan de post gebruikt werden om een directe relatie aanbieder-afnemer tot stand te brengen (pers, radio, telefoon en televisie) werd de benaming 'direct mail' als indicator voor een directe relatie vervangen door het ruimere begrip 'direct marketing'. Typerend voor direct 
marketing is dat een aanbieder die aanvankelijk op traditionele wijze via tussenschakels levert in een later stadium deze tussenschakels passeert en direct aan eind- afnemers gaat leveren. Ook ter inkoopzijde van de organisatie kan DM een rol spelen. Daar geldt dat de betrokken onderneming zich met passering van tussenschakels op de uiteindelijke leverancier richt. Omdat we bij marketing echter meestal eerder aan de 'afzetkant' denken dan aan de 'inkoopkant' zullen we onze artikelen beperken tot de afzetgerichte DM.

Bovenstaande beschouwingen impliceren dat we direct marketing beschouwen als een strategie waarbij gebruik wordt gemaakt van klassieke concepten zoals marktsegmentatie, segmentatiestrategieën en gebruik van de marktinstrumenten, maar waarbij wel een specifieke inhoud aan deze concepten wordt gegeven. Dit betekent dat een DM-strategie tevens een afwijkend systeem van activiteiten met zich mee brengt.

Direct marketing definiëren we dan ook als: een marketingstrategie als ook een systeem van marketingactiviteiten die gericht zijn op het tot stand brengen van een structurele (dat wil zeggen duurzame) directe relatie tussen een aanbieder en zijn uiteindelijke afnemers. Hierbij neemt de aanbieder activiteiten van de ('traditionele') tussenhandel over.

De afnemers kunnen zowel individuele finale consumenten zijn als bedrijfshuishoudingen. (Men spreekt in dit laatste geval van 'business-to businessmarketing'). We zullen ons, zoals al eerder opgemerkt in deze artikelen, op de direct marketing gerichte finale consumenten concentreren.

Toepassing van direct marketing impliceert het gebruik van directe communicatiemiddelen. Deze communicatiemiddelen kunnen in samenhang met de meer traditionele communicatiemiddelen worden gehanteerd. Ook is het mogelijk om alleen de meest traditionele media te hanteren. We zullen aan de hand van de diverse media die gebruikt kunnen worden, diverse vormen van direct marketing onderscheiden:

1 DM met overwegend gebruik van massamedia zoals televisie of dag- en weekbladen. Hierbij wordt de communicatie rechtstreeks op de doelgroep afgestemd. De afnemer uit deze doelgroep wordt dan in de gelegenheid gesteld direct en zelfstandig te reageren (OHRA-, FBTO, Centraal Beheerverzekeringen, Direktbank). Hierbij wordt bij inzet van persmedia veel gebruik gemaakt van couponadvertenties.

2 DM per post of telex: mail-order selling (met behulp van een 'direct mail') zoals bij bloembollen: Bakker, Stassen en internationaal: Breck Holland; of postorderverkoop met behulp van een catalogus zoals bij postorderbedrijven (Wehkamp, Neckermann).

3 DM met behulp van telefonische verkoop (Haagse Post, Kluwer handboeken). Deze vorm van DM wordt ook wel telemarketing genoemd of 'telephone selling' '.

4 DM met behulp van persoonlijke verkoop aan finale afnemers. Zijn deze afnemers consumenten, dan spreken we van colportage ofwel van 'on promise selling' of 'direct selling'. Soms wordt gebruik gemaakt van het inzetten van vertegenwoordigers (zoals bijvoorbeeld bij encyclopedieën). Soms vin- 
den demonstraties plaats bij consumenten thuis (Tupperware plastic, Amway schoonmaakprodukten, Avon schoonheidsmiddelen). Deze vorm van DM wordt ook wel aangeduid als de 'person-to-person' benadering. Soms vindt men ook de benaming 'directe verkoop' 2 .

$5 \mathrm{DM}$ met behulp van interactieve apparatuur (tele-shopping), zoals bij interactieve kabeltelevisie. Commerciële informatie kan hierbij worden aangeboden via de kabel-TV waarbij door middel van speciale randapparatuur de consument kan reageren. (Bildschirmtext, Minitel en Prestel). Het aanbod kan via het beeldscherm getoond worden via een door de PTT of een particuliere onderneming beheerde computer. Afnemers kunnen deze informatie opvragen en vervolgens bijvoorbeeld via een aangesloten 'personal'-of 'home computer' hun bestelling doen.

$6 \mathrm{Bij}$ DM kunnen ook combinaties van media worden ingeschakeld. Eerst wordt bijvoorbeeld 'gemailed', waarna telefonisch contact met consumenten uit de doelgroep gezocht wordt. Daarna kan de persoonlijke verkoper aan de slag; zie figuur 1 .

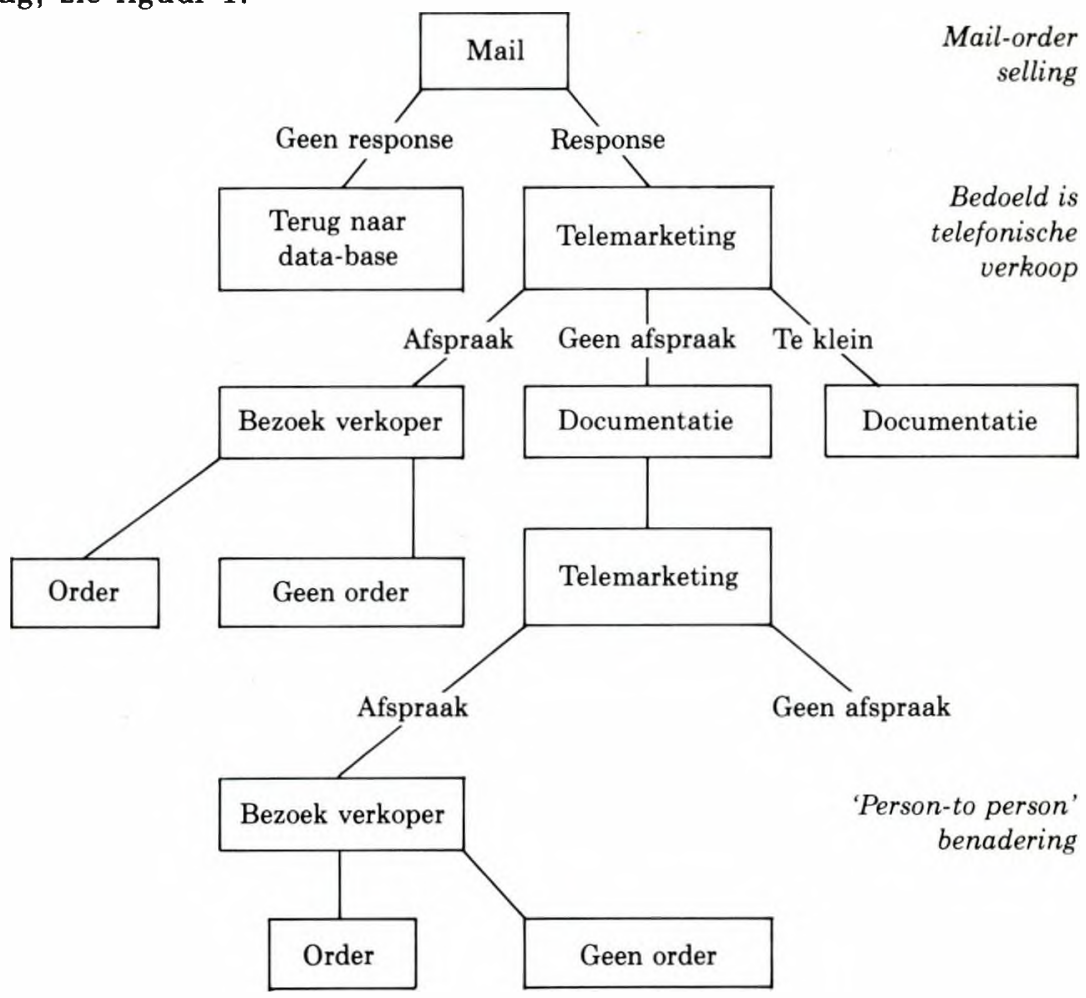

Figuur 1: DM met gebruikmaking van combinaties van media.

Bron: gebaseerd op een advertentie van het fullservice direct marketing bureau 'Target Direct Marketing' in Bijlage Direct Marketing, Adformatie, 16 april 1986, blz. 20 .

De hiervoor genoemde direct marketingtoepassingen gaan in feite uit van een gericht aanbodsinitiatief van de zijde van de onderneming. Toch zijn deze 
vormen van DM als 'traditioneel' te beschouwen omdat er al met vormen van DM wordt geëxperimenteerd waarbij het initiatief vanuit de afnemer voorop staat. Voorbeelden hiervan zijn het op telefonisch verzoek verstrekken van levensmiddelen ('James'-experiment van Ahold) en het telefonisch dan wel per computer opvragen van produktinformatie, gekoppeld aan een bestelsysteem waarbij een creditcard of betaalpas de toegang verschaft en de prijzen van de te bestellen artikelen relatief laag zijn (Comp-U-card).

We willen bij onze tot dusver gegeven beschouwingen twee kanttekeningen plaatsen:

1 We hebben een duidelijk onderscheid aangebracht tussen doelstelling en middelen van DM. De doelstelling kwam tot uitdrukking in onze definitie. Deze doelstelling luidt: het tot stand brengen van een structurele directe relatie tussen aanbieder en afnemer. Daarbij kan men diverse middelen hanteren zoals massamedia, direct mail, de telefoon, het brengen van bezoeken en interactieve apparatuur. Als men gedrukte media gebruikt dan kiest men, zoals al opgemerkt, vaak voor couponadvertenties. De lezers van de gebruikte media worden dan uitgenodigd om door retournering van een ingevulde coupon een relatie met een organisatie aan te gaan. Dit kan tot gevolg hebben dat de betreffende organisatie informatie stuurt, een vertegenwoordiger van de organisatie een bezoek bij de respondent aflegt of het produkt dat in de couponadvertentie vermeld wordt, geleverd wordt. Nu wordt direct marketing nogal eens synoniem geacht met couponadvertenties alsook met direct mail; samen ook wel 'directe responsreclame' genoemd. Deze middelen bakenen echter niet het probleemveld direct marketing af. Zo kunnen ook adverteerders die geen structurele directe relatie met afnemers tot stand willen brengen met couponadvertenties werken.

2 In veel definities van 'direct marketing' legt men de nadruk op het opwekken van directe reacties. Een voorbeeld is de definitie van DM in het Handboek Direct Marketing ${ }^{3}$ die luidt:

'Direct marketing is het totaal van activiteiten waarmee produkten en diensten aan marktsegmenten worden aangeboden in één of meer media met informatieve bedoelingen en/of met het doel directe reacties op te wekken van huidige en toekomstige klanten door middel van directe communicatiemiddelen zoals brieven, telefoongesprekken en couponadvertenties'. Een directe reactie vormt ons inziens echter geen uniek kenmerk van direct marketing. Acties zoals prijskortingen, het verstrekken van cadeaus bij het produkt en prijsvragen leveren ook deze reacties op. Naar onze mening is het kenmerk van direct marketing dan ook niet het gebruik van directe communicatiemiddelen, en/of het opwekken van directe reacties doch het tot stand brengen van een structurele directe relatie tussen aanbieder en vragers. Hierbij speelt het tot stand brengen van herhalingsaankopen een sleutelrol.

De vraag dringt zich op welke aanbieders nu zo'n directe structurele relatie met hun uiteindelijke afnemers tot stand kunnen brengen. Dit kunnen organisaties in alle geledingen van de bedrijfskolom zijn. Tamelijk veel 'producenten' van diensten maken gebruik van direct marketing: verzekeringsmaatschappijen, banken, aanbieders van 'creditcards', en reisorganisaties. Ook fabrikanten van tastbare goederen maken gebruik van 
direct marketing al dan niet in samenwerking met hun 'dealers'. Men denke bijvoorbeeld aan autofabrikanten, geneesmiddelenfabrikanten en uitgevers. De postorderverkoop wordt veelal uitgeoefend door distribuanten. Dit kunnen 'grossiers' (Wehkamp) doch ook detaillisten zijn. Hiervóór noemden we reeds Ahold; andere voorbeelden zijn Ter Meulen Post en Prénatal.

Zowel 'profit'- als 'non-profit-organisaties kunnen voor een DM-strategie kiezen. Voorbeelden van 'non-profit-organisaties' die voor deze strategie gekozen hebben zijn organisaties die fondsen werven zoals het Astma fonds, het Nederlands Bijbelgenootschap, Removos en het Leger des Heils. In de Verenigde Staten komt $90 \%$ van de fondsenwerving van dergelijke organisaties tot stand door middel van $\mathrm{DM}^{4}$.

$\mathrm{Al}$ eerder merkten we op dat het tot stand komen van een directe structurele relatie niet alleen plaatsvindt met finale afnemers, maar ook met industriële afnemers. Men spreekt hier over 'business to business-direct marketing'. Bekende voorbeelden zijn: Overtoom ('Den Dolder'), een bedrijf dat sinds 1946 per catalogus aan bedrijven verkoopt; Hocatex (bedrijfskleding); Varekamp (vervoer industriële produkten) en Kleenex (celstof-handdoeken). Omdat er bij industriële marketing veelvuldig van een structurele directe relatie sprake is, is het moeilijk om te bepalen of er al dan niet sprake is van direct marketing. Daar echter waar 'klassieke' tussenschakelfuncties (zoals transport en opslag of facilitaire tussenschakelfuncties als winkelverkoop) worden overgeslagen kunnen we binnen het kader van onze definitie van DM spreken.

\section{Achtergronden van de ontwikkeling van DM op de consumen- tenmarkt: invloed van omgevingsvariabelen}

In veel DM-literatuur wordt beklemtoond dat DM een volstrekt eigen erkenning verdient en beschouwd moet worden als een individueel toepassingsgebied van marketing. Ons inziens is DM, gegeven de definitie, verschillend van 'traditionele' marketing door het rechtstreekse karakter van geld-, informatie- en goederenstroom tussen een aanbieder en zijn uiteindelijke afnemer. Er is met andere woorden sprake van rechtstreekse communicatie, rechtstreekse levering van artikelen en rechtstreekse betaling. DM wordt daarbij vaak verricht door bedrijven die aanvankelijk traditioneel (dat wil zeggen indirect) communiceerden, leverden of lieten betalen. Hieruit vloeien verschillen voort die met name betrekking hebben op segmentatie en segmentatiestrategieën en de marketing-mix-beslissingen.

De erkenning van het eigen karakter van DM brengt ons tot de vraag welke factoren nu verantwoordelijk kunnen worden gesteld voor de groei in ontwikkeling en het succes van DM. Te denken valt aan de volgende ontwikkelingen in de omgeving van de onderneming:

1 Ontwikkelingen in de economische omgeving. De daling van het vrij besteedbare inkomen in de eerste helft van de jaren tachtig heeft veel consumenten op het spoor van het 'thuiswinkelen' en 'thuisbankieren' gezet. Dit is 
zeer sterk het geval wanneer door uitschakeling van distribuanten de prijzen van de geleverde produkten en diensten dalen. Dit verklaart voor een belangrijk deel het succes van sommige verzekeringsmaatschappijen die 'rechtstreeks', dat wil zeggen zonder tussenpersonen, werken en daardoor goedkoper kunnen opereren.

2 Ontwikkelingen in de technologische omgeving. De volgende technologische ontwikkelingen hebben een positieve invloed op de ontwikkeling van DM:

a Het toenemend gebruik van automatische giro- en bankbetalingen en 'creditcards' door consumenten.

b Het toenemend gebruik van nieuwe informatietechnologieën zoals computersystemen en scanningsapparatuur. Hierdoor kan men steeds meer doen met adreslijsten voor bedrijven die DM overwegen. Toepassing van deze technologieën leidt ook tot het beter verkrijgen en onderhouden van adresbestanden. ${ }^{5}$

c De mogelijke groei van direct marketing in de toekomst zal mede afhangen van de effecten van de toepassing van de vele nieuwe mediatechnologieën. Enkele voorbeelden van deze technologieën die voor de ontwikkeling van DM van belang zouden kunnen zijn, zijn:

- de groei in toepassingsmogelijkheden van het kabel $T V$-net en videotex. Het wordt voor de producenten in toenemende mate mogelijk om hun produkten via het beeldscherm (naar geografisch gebied gedifferentieerd) aan hun afnemers aan te bieden. Deze vorm van direct marketing ('teleshopping') kan met name bij marketing van diensten een belangrijke rol gaan spelen; 6

- de ontwikkeling in twee-richting-interactieve kabelsystemen.

Het wordt voor de consument in toenemende mate mogelijk om informatie van databanken op te vragen en produkten via de kabel bij de producent te bestellen;

- verdergaande toepassing van videocassettes en videodiscs in plaats van gedrukte catalogi.

3 Ontwikkelingen in de culturele en sociale omgeving.

In de samenleving zijn enkele tendensen waar te nemen die een positieve invloed op direct marketing hebben. Een belangrijke tendens is bijvoorbeeld de individualiseringstendens ${ }^{7}$. Steeds meer mensen creëren hun eigen wereld met de daarbij behorende eigen produkten. Ook herwaardering van vrije tijd heeft een positieve invloed op DM. Door het thuis winkelen spaart men tijd uit.

4 Ontwikkelingen in demografische omgevingsvariabelen. Een groot aantal ontwikkelingen in demografische variabelen zijn van belang voor de groei van DM:

a het toenemend aantal vrouwen dat ingeschakeld is in het arbeidsproces.

Deze vrouwen hebben minder tijd om te winkelen en voor een aantal van hen kan DM een uitkomst bieden;

$b$ de toename in het aantal éénpersoonshuishoudens en tweepersoonshuishoudens waar beide personen werkzaam zijn. Ook voor deze huishoudens geldt dat zij minder tijd hebben om te winkelen;

c de vergrijzing van de bevolking heeft ook een positieve invloed op DM. We 
hebben in de vorige paragraaf reeds melding gemaakt van het 'James'experiment. Hierbij worden levensmiddelen - na bestelling - thuisbezorgd. Dit is voor ouderen die slecht ter been zijn zeer interessant. Het Amerikaanse winkelconcern Sears heeft (met veel succes) een postorderbedrijf opgericht dat zich specifiek richt op personen die ouder zijn dan 55 jaar.

Naast de ontwikkeling in deze omgevingsvariabelen spelen ontwikkelingen bij een aantal marktpartijen een belangrijke rol. Door de toegenomen macht in veel distributiekanalen proberen een aantal fabrikanten de handel te ontlopen door rechtstreeks aan consumenten te leveren. Dit verschijnsel doet zich zowel op producenten- als op grossiersniveau voor. Van deze ontwikkeling 'profiteert' DM. Door rechtstreeks met finale afnemers in contact te treden kan men kosten (marges, kosten van vertegenwoordigers en/of accountmanagement) besparen. Bovendien heeft men de communicatie met de finale afnemer zelf in de hand. Ook vinden er ontwikkelingen plaats bij distributeurs die zodanig zijn dat er meer ruimte vrijkomt voor DM. We doelen hierbij op de volgende ontwikkelingen in de traditionele handel:

- de afnemende service in winkels;

- de afname van het winkelplezier door lange wachttijden;

- onvoldoende parkeergelegenheden;

- toenemende ondeskundigheid van het personeel;

- consument-onvriendelijke openingstijden en

- assortimentsinkrimping. ${ }^{8}$

Erkend moet worden dat er ook vele factoren zijn die de mogelijke groei van DM belemmeren dan wel rechtstreeks tegenwerken.

Enkele voorbeelden:

- De terughoudendheid van de consument. Het winkelen heeft voor de consument meerdere waarden dan alleen het kopen van produkten. De 'sfeer' is van belang, speciaal in het tijdperk waarbij mensen steeds meer vrije tijd ter beschikking hebben. Tevens nemen velen daarin - gesteund door consumentenorganisaties - een terughoudende houding aan ten opzichte van DMmethoden (in verband met de aantasting van hun privacy (zie ook hierna)). - Minder geschikte produkten. Er zijn altijd produkten die minder geschikt zijn voor DM. Beperkingen worden opgelegd door bijvoorbeeld een uitgesproken breekbaarheid en bederfelijkheid. Ook produkten als geneesmiddelen en produkten die van demonstraties afhankelijk zijn kunnen voor DM minder geschikt zijn.

- De voorzichtigheid van producenten. Des te sterker de relatie van de producent met de traditionele distributiekanalen des te minder interesse hij zal hebben in DM. Ook geldt dit naarmate hij machtiger is met betrekking tot zijn marktpositie (bijvoorbeeld in termen van marktaandeel). De overgang naar DM kan dan teveel onzekerheden met zich meebrengen, alsook te hoge additionele kosten.

- De mogelijke reacties van de bedreigde tussenhandel. Een sterke tussenhandel kan reageren met een mogelijke serviceverbetering en/of assortimentsverbreding. Ook kan deze meer aandacht besteden aan de 'up-to-date'- 
kenmerken van het produkt. Bij DM is het produkt namelijk minder snel aan te passen omdat men veelal werkt met al voorgedrukte catalogi, reclamespots, 'direct mail', enz.

- Houding consumentenorganisaties. In verband met de aantasting van de privacy en misleidende suggestiviteit zijn de consumentenorganisaties soms zéér kritisch ten aanzien van sommige ontwikkelingen in DM. Een goed voorbeeld hiervan was de actie van de Consumentenbond in 1986 tegen de door de PTT en de Readers Digest geïnitieerde handel in adressenbestanden.

De mogelijke groei van DM zal vooral sterk afhangen van de mate waarin de consumenten in staat zullen zijn de nieuwe DM-media-technologieën in de toekomst te gaan gebruiken. Daarnaast spelen vele externe omgevingsvariabelen een rol, zoals hoogte voor posttarieven, privacy-beschermende wetten, verdergaande toepassingen van creditcards en de ontwikkelingen in de traditionele detailhandel.

Verwacht mag worden dat als gevolg van de groei-belemmerende en 'tegenwerkende krachten' als ook van de onderlinge concurrentie vele organisaties die $\mathrm{DM}$-activiteiten ontplooien náast $\mathrm{DM}$ een indirect kanaal zullen gaan ontwikkelen. Anderzijds zullen vele traditioneel leverende organisaties door de toepasbaarheid van nieuwe technologieën DM-methoden gaan gebruiken. We kunnen dan ook verwachten dat op de lange termijn de grens tussen de organisaties die alleen DM toepassen en organisaties die dit niet zullen doen, zal gaan vervagen. In concreto: op de consumentenmarkt zullen organisaties gaan opereren die 'store-retailing' en 'non-store-retailing' gaan combineren. ${ }^{9}$

De in dit artikel besproken ontwikkelingen in externe omgevingsvariabelen hebben geleid tot een sterke ontwikkeling van DM in de afgelopen jaren. Dit is onder meer af te leiden uit onderstaande tabel waarin de uitgaven aan rechtstreekse reclame nader uitgesplitst zijn.

\begin{tabular}{|c|c|c|c|c|c|c|c|c|c|c|c|}
\hline & $\begin{array}{l}1976 \\
\min \end{array}$ & $\begin{array}{l}1977 \\
m l n\end{array}$ & $\begin{array}{l}1978 \\
m l n\end{array}$ & $\begin{array}{l}1979 \\
m \ln \end{array}$ & $\begin{array}{l}1980 \\
m l n\end{array}$ & $\begin{array}{l}1981 \\
m \ln .\end{array}$ & $\begin{array}{l}1982 \\
m \ln \end{array}$ & $\begin{array}{l}1983 \\
m l n\end{array}$ & $\begin{array}{l}1984 \\
m l n\end{array}$ & $\begin{array}{l}1985 \\
m \ln \end{array}$ & $\begin{array}{l}1986 \\
m l n\end{array}$ \\
\hline $\begin{array}{l}\text { Drukwerk/handling } \\
\text { Verspreiding via }\end{array}$ & - & & 724 & 778 & 802 & 1.000 & 1.138 & 1.248 & 1.608 & 1.961 & 2.034 \\
\hline $\begin{array}{l}\text { PTT } \\
\text { Verspreiding anders }\end{array}$ & 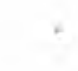 & . & 221 & 237 & 244 & 250 & 290 & 290 & 315 & 429 & 435 \\
\hline $\begin{array}{l}\text { dan via de PTT } \\
\text { Gesponsorde bladen } \\
\text { (schatting) }\end{array}$ & 2 & . & 75 & 82 & 85 & 108 & $\begin{array}{r}120 \\
(100)\end{array}$ & $\begin{array}{r}120 \\
(150)\end{array}$ & $\begin{array}{r}159 \\
(150)\end{array}$ & $\begin{array}{r}169 \\
(165)\end{array}$ & $\begin{array}{r}182 \\
(143)\end{array}$ \\
\hline
\end{tabular}

Totaal rechtstreekse reclame $\begin{array}{lllllllllll}860 & 985 & 1.020 & 1.097 & 1.131 & 1.358 & 1.548 & 1.658 & 2.082 & 2.559 & 2.654\end{array}$

Tabel 1: Bestedingen Rechtstreekse reclame 1976-1986

Bron: VEA Media \& Research Commissie, Reclamebestedingen in Nederland 1986, Amsterdam, blz. 37 . 
Uit deze tabel blijkt de spectaculaire groei van rechtstreekse reclame. Er blijkt echter ook uit dat deze groei in het laatste jaar is afgenomen ten opzichte van voorgaande jaren. De ontwikkeling van rechtstreekse reclame, zoals die is weergegeven, geeft helaas geen inzicht in de verkopen die het gevolg zijn van direct marketingsactiviteiten. Dit inzicht is, in Nederland althans, ook (nog) niet te krijgen. Enig inzicht in het belang van DM kunnen we wel ontlenen aan Amerikaanse literatuur. Zo was de afzet van de leden van de Direct Marketing Association (DMA) in 1978: 26,2 miljard dollar, in 1983: 28 miljard dollar en in 1985: 32,1 miljard dollar. ${ }^{10}$ De leden van de DMA bestaan voornamelijk uit postorderbedrijven. Banken, verzekeringsmaatschappijen en andere organisaties die financiële diensten verlenen vallen hierbuiten. Wanneer de afzet van deze organisaties en de telefonische en persoonlijke verkoop van consumentenprodukten en industriële produkten hierbij wordt betrokken komen we aan schattingen die in de buurt van de 200 miljard dollar liggen (1983). " Wat wellicht meer zegt, is dat in 1978 , de postorderverkopen $12 \%$ uitmaakten van de afzet in 'general merchandise'. ${ }^{12}$ Wanneer we de verkopen in supermarkten, restaurants, benzinestations en autodealers buiten beschouwing laten, maakten de DMbestedingen in $198337.5 \%$ uit van de bestedingen in de hiervoor niet genoemde detailhandelsvestigingen.

\section{Conclusie}

We hopen in dit eerste artikel te hebben duidelijk gemaakt, dat direct marketing een structureel verschijnsel is. Direct marketing kan worden gezien als een strategie. Maar ook als een systeem van marketingactiviteiten. Omdat de DM-manager daarbij de activiteiten van de tussenhandel overneemt en omdat directe communicatie wordt gehanteerd, worden distributiebeslissingen en communicatiebeslissingen sterk geïntegreerd.

In dit artikel stond de benadering van de consumentenmarkt centraal. De achtergronden van de ontwikkeling op deze markt wettigen de veronderstelling dat de grens tussen DM en 'traditionele' marketing op den duur zal vervagen. In een volgend artikel zullen we de operationalisering van DM bespreken: het eigene van segmentatie en segmentatiestrategieën bij DM alsmede de mogelijkheden en beperkingen van de marketingmix-beslissingen.

\section{Literatuur}

Baier, M. (1983): Elements of Direct Marketing, McGraw-Hill, Inc., New York.

Bernstein, R.A. and Associates: Succesful Direct Selling, Prentice-Hall, Inc., Englewood Cliffs, N.J.

Hermsen, B.J.A. (1986): Telemarketing: een antwoord op de stijgende verkoopkosten, Markeur, jaargang 1986, nr. 2, blz. 20-21.

Janssen, P. en R. Cloïn (1986): Telemarketing: (Moder(m)nisme) met mogelijkheden, Tijdschrift voor Marketing, jrg. 20, nr. 12, blz. 4-10.

Kooij, H. (1986): PTT Post, uw partner in direct mail, Markeur, jaargang 1986, nr. 2, blz. 23-27.

Lakatos, P.A.M. en R.M. van Kralingen (1985): Naar 1990, een kwestie van Tijd en Geld, Innovatiereeks, Elsevier, Amsterdam, Brussel. 
Leeflang, P.S.H. (1987): Probleemvelden in marketing, MAB, jrg. 61, nr. 10, blz. 374-378.

Roomer, J. (1984): Evaluatie van definities en karakteristieken in Roomer, J. (red.), Handboek Direct Marketing, Kluwer/Samsom, Deventer/Alphen aan den Rijn, blz. A.4.1-01 A.4.1-22.

Roomer, J. (1986): Termen, Adformatie, 11 december 1986, blz. 63-64.

Scroge, M. (1980): Socio-economic Trends Cause High Growth in Nonstore Marketing Field, Marketing News, Vol.XIII, nr. 16, blz. 1-3.

Tixier, D. (1986): New Ways to Increase Customer Loyalty, presentatie Direct Marketing Congres, september 1986, Amsterdam.

\section{Noten}

1 Zie bijuoorbeeld Hermsen (1986); Janssen, Cloin (1986). Met bijuoorbeeld Roomer(1986), prefereren we de term telefonische verkoop.

2 'Direct selling is the technique of approaching a customer on a person-to-person basis, either with a group approach (as in (in-home) partyplan) or individually, one-to-one to offer products conveniently with a personal service emphasis' (Bernstein, 1984, blz. 4).

3 Zie Roomer (1984, blz. A 4.1-05).

4 Baier (1983, blz. 15).

5 Zie voor een illustratie Kooij (1986).

6 Zie ook Adformatie, 27 november 1986, blz. 36.

7 Lakatos, Van Kralingen (1985) en Tixier (1986).

8 Zie bijvoorbeeld Scroge (1980); Quelch, Takeuchi (1981).

9 Quelch, Takeuchi (1981).

10 Zie respectievelijk Scroge (1980); Marketing News 23 november 1984, blz. I en Direct marketing Association (1986), Industry Statistics Survey, October 1986, blz. 34.

11 Zie Marketing News van 23 november 1984, blz. 1.

12 Zie Scroge (1980). 